University of Nebraska - Lincoln

DigitalCommons@University of Nebraska - Lincoln

USDA National Wildlife Research Center - Staff

Publications

U.S. Department of Agriculture: Animal and Plant Health Inspection Service

October 2004

\title{
Herbivore experience with plant defense compounds influences acquisition of new flavor aversions
}

\author{
Bruce A. Kimball \\ USDA/APHIS/WS/NWRC, bruce.kimball@ars.usda.gov \\ Dale L. Nolte \\ USDA-APHIS-Wildlife Services, Dale.L.Nolte@aphis.usda.gov
}

Follow this and additional works at: https://digitalcommons.unl.edu/icwdm_usdanwrc

Part of the Environmental Sciences Commons

Kimball, Bruce A. and Nolte, Dale L., "Herbivore experience with plant defense compounds influences acquisition of new flavor aversions" (2004). USDA National Wildlife Research Center - Staff Publications. 19.

https://digitalcommons.unl.edu/icwdm_usdanwrc/19

This Article is brought to you for free and open access by the U.S. Department of Agriculture: Animal and Plant Health Inspection Service at DigitalCommons@University of Nebraska - Lincoln. It has been accepted for inclusion in USDA National Wildlife Research Center - Staff Publications by an authorized administrator of DigitalCommons@University of Nebraska - Lincoln. 


\title{
Herbivore experience with plant defense compounds influences acquisition of new flavor aversions
}

\author{
Bruce A. Kimball ${ }^{\mathrm{a}, \mathrm{b}, *}$, Dale L. Nolte \\ ${ }^{\mathrm{a}}$ USDA/APHIS/WS/NWRC, 4101 LaPorte Avenue, Fort Collins, CO 80521, USA \\ ${ }^{\mathrm{b}}$ Graduate Degree Program in Ecology, Colorado State University, Fort Collins, CO 80523, USA \\ ${ }^{\mathrm{c}}$ USDA/APHIS/WS/NWRC, 9730-B Lathrop Industrial Drive, Olympia, WA 98512, USA
}

Accepted 8 October 2004

\begin{abstract}
Multiple experiments were conducted with a mammalian herbivore to determine how experience with plant secondary metabolites (terpenes and tannins) influenced acquisition of new aversions to diets containing these same plant metabolites. Goats (Capra aegagrus hircus) were employed as behavioral models for this study. Twenty-four subjects were assigned to three treatment groups that received 20 days of experience with test diets: (A) terpene diet only; (B) tannin diet only; and (C) terpene and tannin diets offered singly on alternate days. In experiment 1 , all subjects were offered both diets in a two-choice test to determine if experience affected diet preference. Both treatments $\mathrm{A}$ and $\mathrm{B}$ demonstrated significant preferences for the terpene diet, while treatment $\mathrm{C}$ subjects did not exhibit a diet preference.

Both diets were offered to all subjects and immediately followed with a $150 \mathrm{mg} / \mathrm{kg}$ dose of lithium chloride $(\mathrm{LiCl})$ in experiment 2 . A two-choice preference test was conducted to determine if lithiuminduced toxicosis would be associated with the least familiar diet. As in experiment 1 , treatments $\mathrm{A}$ and $\mathrm{B}$ preferred terpene diet while treatment $\mathrm{C}$ did not demonstrate a preference. Lithium chloride exposure was specifically paired with one of the test diets in experiment 3 . A two-choice preference test demonstrated that treatments $\mathrm{A}, \mathrm{B}$, and $\mathrm{C}$ acquired aversions to tannin diet when it was paired with $\mathrm{LiCl}$ administration. However, terpene-paired $\mathrm{LiCl}$ administration did not produce an aversion to the terpene diet in treatments $\mathrm{A}$ and $\mathrm{B}$. Treatment $\mathrm{C}$ preferred tannin diet when the terpene diet was paired with $\mathrm{LiCl}$.
\end{abstract}

* Corresponding author. Tel.: +1 970266 6069; fax: +1 9702666063 .

E-mail address: bruce.a.kimball@aphis.usda.gov (B.A. Kimball). 
A novel flavor was added to the choice of diets in experiment 4 . All subjects were offered citric acid (CA), terpene, and tannin-containing diets and immediately dosed with LiCl. Subjects that acquired aversions to the tannin diet in experiment 3 continued to avoid tannin diet in experiment 4 and preferred terpene diet while eating significant quantities of the novel CA diet. Only treatment $\mathrm{C}$ subjects with previous terpene-paired $\mathrm{LiCl}$ exposures demonstrated aversions to the $\mathrm{CA}$ diet. These results have implications for the conduct of flavor aversion studies and the application of flavor aversion learning (FAL).

Published by Elsevier B.V.

Keywords: Diet selection; Flavor aversion learning (FAL); Plant secondary metabolites; Tannins; Terpenes

\section{Introduction}

Morphological and physiological differences among herbivores influence their capacity to tolerate or utilize specific foods. However, recognition of these differences should not prohibit acknowledgment of elementary processes common among herbivores. Namely phytochemicals initiate affective and cognitive processes that enable herbivores to control nutrient and toxin intake under changing nutritional needs and environmental conditions (Provenza, 1995c). Postingestive feedbacks are integrated with associated flavors to form preferences or aversions. Furthermore, flavor may potentiate preferences and aversions for other sensory attributes (Provenza, 1995a). Among the many plant secondary metabolites that participate in these processes of diet selection, terpenes and tannins are widespread.

Numerous woody plants contain terpenes and/or tannins that reduce intake of mammalian herbivores (i.e., they are antifeedants). Mammalian forage preference for a variety of plants has been linked to monoterpenes (Dimock et al., 1976; Farentinos et al., 1981; Bell and Harestad, 1987; Reichardt et al., 1990; Bryant et al., 1991, 1992; Snyder, 1992; Estell et al., 1998; Kimball et al., 1998). The antifeedant properties of monoterpenes are mediated by their toxic properties (Bryant et al., 1991). Among other effects, monoterpenes inhibit acetylcholinesterase activity in mammals (Miyazawa et al., 1997) and may cause diuresis (Dearing et al., 2002).

Tannins defend plants against fungi and bacteria as well as herbivores through their toxic properties and by inhibiting digestion (Robbins et al., 1987). Mammalian plant avoidance has been correlated with tannin content for many species (Robbins et al., 1987; Clausen et al., 1990; Roy and Bergeron, 1990; Sunnerheim-Sjoberg and Hamalainen, 1992; Rangen et al., 1994; McMahon et al., 2000). Tannins reduce forage digestibility in ruminants and can cause ulcers in the gastrointestinal tract (Dawson et al., 1999).

A recent study with lambs demonstrated that prior experience with tannin- and terpenecontaining foods influenced diet selection when several toxin-containing foods were offered (Villalba et al., 2004). Subjects ate more toxin-containing foods when they had experience with that food. Experience with a toxic food may produce physiological and morphological changes in the individual that increase tolerance for the toxin (Distel and Provenza, 1991). Furthermore, total intake of multiple toxin-containing foods increases when toxins are complimentary (Burritt and Provenza, 2000). Complimentary toxins are likely to be detoxified via different pathways, allowing the total intake of multiple toxic foods to exceed intake of a single toxic food. 
This study was designed to evaluate how prior experience with toxin-containing foods influences acquisition of new flavor aversions. This information can be useful for interpreting herbivore responses to aversive events, particularly in the evaluation of applied flavor aversion learning (FAL). It is conceivable that prior learning could potentiate formation of new aversions and/or prevent aversive events from being associated with the intended flavor cue.

Subjects were provided varying experiences with terpene- and tannin-containing foods and a series of experiments assessed how experience and aversive conditioning influenced subsequent diet selection. Sequential experiments included exposure to an unconditional stimulus (lithium chloride, $\mathrm{LiCl}$ ) following free choice of terpene- and tannin-containing foods, pairing of $\mathrm{LiCl}$ exposure with one of the toxin-containing foods, and $\mathrm{LiCl}$ exposure following free choice of the toxin-containing foods and a novel food. A priori hypotheses were formulated from three assumptions: (1) experience with specific plant chemical defenses will generate a tolerance for those defensive compounds; (2) aversions will be more readily associated with less familiar foods; and (3) aversions to familiar foods are difficult to acquire with a single aversive event.

\section{Methods}

\subsection{Subjects}

Twenty-four pigmy goats (Capra aegagrus hircus) identified by ear-tags and group, housed in a small pasture (ca. 1 ha) containing shelter, water troughs, and feed bins, were used in the study. Subjects were placed in individual pens (ca. $1.5 \mathrm{~m} \times 2.5 \mathrm{~m}$ ) daily for 30 min feeding trials and immediately returned to pasture. Subjects were provided access to grass hay following testing and ad libitum access to water throughout the day. The experiments were conducted during the period of 4 November 2002-14 February 2003. Experimental procedures were reviewed and approved by the Institutional Animal Care and Use Committee of the USDA National Wildlife Research Center.

\subsection{Test diets}

Individually penned subjects were offered $500 \mathrm{~g}$ quantities of test foods in $2 \mathrm{~L}$ plastic containers following a $4 \mathrm{~h}$ deprivation. Containers were affixed to the sides of the pens to reduce spilling. Refusals following the $30 \mathrm{~min}$ feeding bouts were measured (mass) and intake was determined by difference. Test diet batches $(25 \mathrm{~kg})$ were formulated from ground alfalfa pellets $(5.0 \mathrm{~kg})$, ground barley $(8.0 \mathrm{~kg})$, ground sugar beet pulp pellets $(8.0 \mathrm{~kg})$, soybean meal $(1.0 \mathrm{~kg})$, and vegetable oil $(1.0 \mathrm{~L})$. This mixture was also employed as the training diet.

Terpene-containing diets were prepared by adding $750 \mathrm{~mL}$ of a terpene solution (Table 1) to each batch of test diet by mixing the solution with the previous vegetable oil. The qualitative composition of the terpene solution was based on previous work with Douglas-fir (Kimball et al., 1998). Terpenes were purchased from Sigma-Aldrich 
Table 1

Terpene solution ingredients used to prepare the terpene diet

\begin{tabular}{rl}
\hline Quantity $(\mathrm{mL})$ & Terpene \\
\hline 1500 & $(1 S)-(-)-\alpha$-Pinene \\
$17(\mathrm{~g})$ & $(1 S)-(-)-$ Camphene \\
250 & $(1 S)-(-)-\beta$-Pinene \\
50 & Myrcene \\
100 & $(1 S)-(+)-3$-Carene \\
5 & $\alpha$-Terpinene \\
13 & $p$-Cymene \\
125 & $(1 S)-(-)-$ Limonene \\
5 & $\gamma$-Terpinene \\
100 & Terpinolene \\
50 & $( \pm)$ Linalool \\
50 & $(1 R)-(-)-$ Terpinen-4-ol \\
7 & $(1 S)-(-)-\alpha$-Terpineol \\
50 & $(1 S)-(-)$-Bornyl acetate \\
50 & Citronellyl acetate \\
5 & $(1 R, 2 S, 7 S, 9 S)-(+)$-Longifolene \\
10 & $(1 R, 9 S)-(-)-\beta-$ Caryophyllene \\
\hline
\end{tabular}

(St. Louis, MO, USA); except for $\beta$-caryophyllene, terpinen-4-ol, $\alpha$-terpineol, and terpinolene, which were purchased from TCI America (Portland, OR, USA).

Tannin-containing diets were produced by adding $1.0 \mathrm{~kg}$ quebracho tannin (Tannin Corp., Peabody, MA, USA) to each batch of test diet. Citric acid (CA) diets were prepared by addition of $220 \mathrm{~g} \mathrm{CA}$ to each batch of test diet. Citric acid was purchased from SigmaAldrich. Separate bins were used for mixing terpene, tannin, training, and CA-diets to minimize cross-contamination. Diets were stored in separate ca. $140 \mathrm{~L}$ covered plastic bins and offered to subjects in feeding containers dedicated to specific diets.

\subsection{Experience}

Subjects were offered training diet for 5 successive days in no-choice tests and intake recorded. Subjects were randomly assigned to one of three treatment groups with subject body mass stratified across treatments. Subjects were offered test diets daily for 20 days according to the study design and intake recorded (Table 2). Treatment A subjects were offered only the terpene diet, while subjects in treatment B were offered only tannin diet for the duration of the experience period. Subjects in treatment $\mathrm{C}$ were offered the two diets, one at a time, on alternating days beginning with terpene diet on day 1 and followed by tannin diet on day 2 , etc.

\subsection{Experiment 1}

Preference was assessed by offering all subjects the test diets in two-choice tests (Table 2). Terpene and tannin test diets $(500 \mathrm{~g}$ each) were offered side-by-side daily for $30 \mathrm{~min}$ and intakes recorded. The two-choice test was conducted for 10 days. During a 
Table 2

Twenty-four subjects were subjected to four sequential experiments according to the following experimental design

\begin{tabular}{|c|c|c|c|c|c|c|}
\hline Procedure & Treatment A & & Treatment B & & Treatment C & \\
\hline Training (5 days) & Training diet & & Training diet & & Training diet & \\
\hline Experience (20 days) & Terpene diet only & & Tannin diet only & & $\begin{array}{l}\text { Terpene and tannin diets } \\
\text { (alternating days) }\end{array}$ & \\
\hline $\begin{array}{l}\text { Experiment } 1 \\
\quad \text { Preference (10 days) }\end{array}$ & $\begin{array}{l}\text { Eight subjects } \\
\text { Terpene diet } \\
\text { vs. tannin diet }\end{array}$ & & $\begin{array}{l}\text { Eight subjects } \\
\text { Terpene diet vs. } \\
\text { tannin diet }\end{array}$ & & $\begin{array}{l}\text { Eight subjects } \\
\text { Terpene diet vs. tannin diet }\end{array}$ & \\
\hline $\begin{array}{l}\text { Experiment } 2 \\
\quad \mathrm{LiCl} \text { exposure ( } 1 \text { day) }\end{array}$ & $\begin{array}{l}\text { Eight subjects } \\
\text { Terpene and } \\
\text { tannin diets }\end{array}$ & & $\begin{array}{l}\text { Eight subjects } \\
\text { Terpene and } \\
\text { tannin diets }\end{array}$ & & $\begin{array}{l}\text { Eight subjects } \\
\text { Terpene and tannin diets }\end{array}$ & \\
\hline Preference (2 days) & $\begin{array}{l}\text { Terpene diet } \\
\text { vs. tannin diet }\end{array}$ & & $\begin{array}{l}\text { Terpene diet } \\
\text { vs. tannin diet }\end{array}$ & & $\begin{array}{l}\text { Terpene diet vs. } \\
\text { tannin diet }\end{array}$ & \\
\hline $\begin{array}{l}\text { Experiment } 3 \\
\text { LiCl exposure ( } 1 \text { day) } \\
\text { Preference ( } 8 \text { days) }\end{array}$ & $\begin{array}{l}\text { Four subjects } \\
\text { Terpene diet } \\
\text { Terpene diet } \\
\text { vs. tannin diet }\end{array}$ & $\begin{array}{l}\text { Four subjects } \\
\text { Tannin diet }\end{array}$ & $\begin{array}{l}\text { Four subjects } \\
\text { Terpene diet } \\
\text { Terpene diet vs. } \\
\text { tannin diet }\end{array}$ & $\begin{array}{l}\text { Four subjects } \\
\text { Tannin diet }\end{array}$ & $\begin{array}{l}\text { Four subjects } \\
\text { Terpene diet } \\
\text { Terpene diet vs. } \\
\text { tannin diet }\end{array}$ & $\begin{array}{l}\text { Four subjects } \\
\text { Tannin diet }\end{array}$ \\
\hline $\begin{array}{l}\text { Experiment } 4 \\
\text { LiCl exposure ( } 1 \text { day) } \\
\text { Preference ( } 8 \text { days) }\end{array}$ & $\begin{array}{l}\text { Eight subjects } \\
\text { Terpene, tannin, } \\
\text { and CA diets } \\
\text { Terpene vs. tannin } \\
\text { vs. CA diets }\end{array}$ & & $\begin{array}{l}\text { Eight subjects } \\
\text { Terpene, tannin, } \\
\text { and CA diets } \\
\text { Terpene vs. tannin } \\
\text { vs. CA diets }\end{array}$ & & $\begin{array}{l}\text { Eight subjects } \\
\text { Terpene, tannin, } \\
\text { and CA diets } \\
\text { Terpene vs. tannin vs. } \\
\text { CA diets }\end{array}$ & \\
\hline
\end{tabular}


12-day intermission between experiments 1 and 2, subjects were maintained on a basal ration of grass hay.

\subsection{Experiment 2}

Subjects were offered training diet for 6 days at the start of experiment 2 . The effect of an aversive event on diet selection was then evaluated by lithium chloride $(\mathrm{LiCl})$ exposure (Table 2). All subjects were offered $100 \mathrm{~g}$ each of the tannin and terpene diets in separate containers for $30 \mathrm{~min}$. Immediately following access to the test diets, subjects were dosed with $\mathrm{LiCl}$ at a rate of $150 \mathrm{mg} \mathrm{LiCl}$ per kg body mass via oral delivery of a $1 \mathrm{~mL}$ gel capsule with a balling gun. Experiment 2 consisted of a single $\mathrm{LiCl}$ exposure.

On the day following exposure, preference was assessed by offering the terpene and tannin diets $(500 \mathrm{~g}$ each) in a two-choice test and recording intake (Table 2). The preference test was conducted for 2 days with 30 min feeding bouts. Subjects were maintained on grass hay for 4 days following experiment 2 before resumption of the study.

\subsection{Experiment 3}

For experiment 3, exposure to $\mathrm{LiCl}$ was paired to a specific diet (terpene-paired or tannin-paired). Within each treatment, half the subjects $(n=4)$ were offered $100 \mathrm{~g}$ terpene diet only while the other four subjects were offered $100 \mathrm{~g}$ tannin diet only on the day of exposure (Table 2). Subjects were randomly assigned to the appropriate diet-pair. The 30min feeding bout with the test diets was followed immediately with a $150 \mathrm{mg} / \mathrm{kg}$ oral dose of $\mathrm{LiCl}$. A preference test was conducted for 8 days with all subjects 1 day after exposure by offering terpene and tannin diets in a two-choice test for $30 \mathrm{~min}$. Experiment 4 immediately followed experiment 3.

\subsection{Experiment 4}

A novel flavor was introduced in experiment 4. All subjects were offered $50 \mathrm{~g}$ each of terpene, tannin, and citric acid diets in individual containers (Table 2). Subjects were orally dosed with $\mathrm{LiCl}(150 \mathrm{mg} / \mathrm{kg})$ immediately after a 30-min feeding bout with the three foods. A preference test was conducted for 8 days with all subjects 1 day after exposure by offering $500 \mathrm{~g}$ each of terpene, tannin, and CA diets in three-choice tests for $30 \mathrm{~min}$ and recording intake.

\subsection{Statistical analyses}

Statistical analyses were conducted to determine the effects of experience and lithiuminduced aversion on diet preference in each experiment. Intake data from the experience period of the study were subjected to a repeated measures analysis of variance (ANOVA) where subject was a random effect, treatment (A, B, or C) was the between-subjects effect, and day the within-subject effect. Main effects and interactions were evaluated using the mixed procedure in SAS (SAS, 1999). Terpene and tannin diet intake were also subjected to separate ANOVAs for data acquired during days 6-20. 
Preference data from experiment 1 were subjected to ANOVA with subject: the random effect, diet (terpene or tannin) and treatment (A, B, or C): the between-subjects effects, and day: the within-subject effect. Intake was the response. Three a priori hypotheses were tested: (1) terpene diet intake will be greater than tannin diet in treatment A; (2) tannin diet intake will be greater than terpene diet in treatment B; and (3) terpene and tannin diet intakes will be similar in treatment $C$. Preference data from experiment 2 were similarly analyzed in a repeated measures design with identical a priori hypotheses tested by linear contrast.

Intake data from the preference test in experiment 3 were similarly analyzed except that a third between-subjects effect was included, i.e., pair, the single diet paired with the aversive event (terpene-paired or tannin-paired). The a priori hypotheses for experiment 3 were the same as experiment 2. Post-hoc comparisons of diet $\times$ pair effects were made on the leastsquare means using the $p$-diff option in SAS (SAS, 1999). For post hoc comparisons, the experiment-wise error rate was controlled by applying the sequential Bonferroni adjustment (Rice, 1989).

Two post hoc contrasts were also analyzed: (1) tannin diet intake of terpene-paired subjects in treatment $\mathrm{C}$ was greater than the average tannin intake of terpene-paired subjects from treatments $\mathrm{A}$ and $\mathrm{B}$; and (2) the average terpene diet intake of terpene-paired subjects in treatments $\mathrm{A}$ and $\mathrm{B}$ was greater than the terpene diet intake of terpene-paired subjects in treatment $\mathrm{C}$.

Experiment 4 data was similarly analyzed by ANOVA with identical effects as experiment 3 , except that diet had three levels (terpene, tannin, or CA diet). One a priori contrast was tested: mean terpene and tannin diet intake will be greater than CA diet intake among all subjects. Two post hoc contrasts were also tested: (1) CA diet intake was greater in treatments $\mathrm{A}$ and $\mathrm{B}$ versus treatment $\mathrm{C}$ for subjects with terpene-paired exposure in experiment 3; and (2) tannin diet intake was higher in treatment $C$ versus treatments $A$ and B for terpene-paired subjects.

\section{Results}

\subsection{Experience}

Analyses indicated a significant treatment $\times$ day interaction $(p<0.0001)$. Tannin diet intake was initially low in both treatments $\mathrm{B}$ and $\mathrm{C}$, but increased to a stable level after about 6 days of experience with the diet (Fig. 1). Treatments A and $\mathrm{C}$ readily consumed terpene diet throughout the experience period with no initial avoidance behavior. Results demonstrate that tannin intake of treatment $C$ was not significantly different from treatment $\mathrm{B}$ after day 6. There was neither significant treatment $\times$ day effect $(p=0.265)$, nor treatment effect $(p=0.553)$. However, treatment $\mathrm{C}$ intake of the terpene diet tended to be lower than treatment A for most feedings during the period of days 6-20 (Fig. 1). The treatment $\times$ day interaction was highly significant $(p=0.0011)$.

\subsection{Experiment 1}

Analyses revealed a significant treatment $\times$ diet $\times$ day interaction, indicating diet selection varied over time and was influenced by experience $(p<0.0001)$. Data do not 


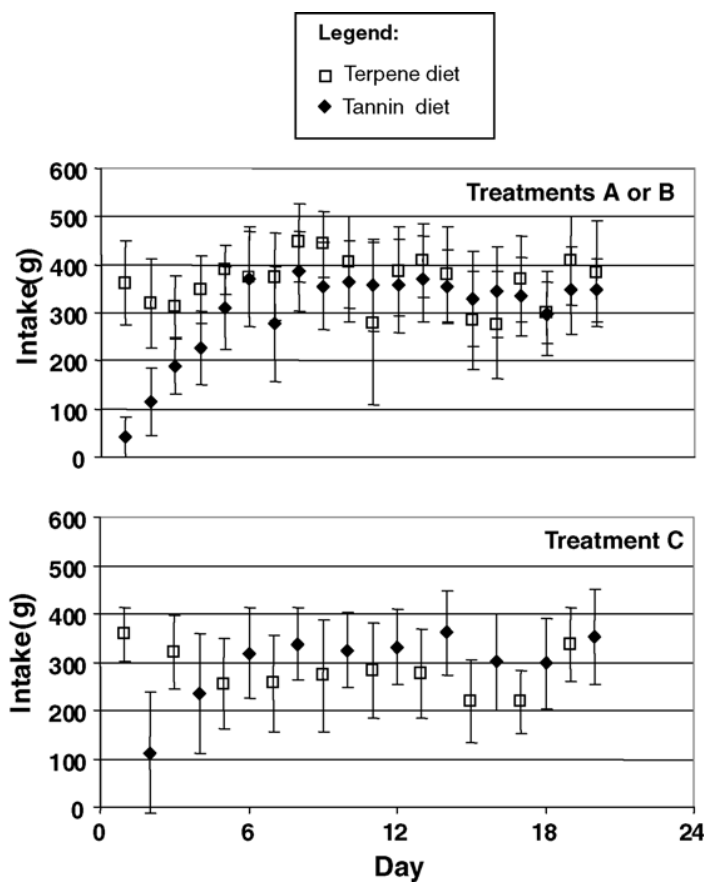

Fig. 1. Daily intake of test foods during the 20-day experience period of the study according to treatment group. Treatment A received only terpene diet, treatment $\mathrm{B}$ only tannin diet, and treatment $\mathrm{C}$ alternated the diets daily.

support the hypothesis that familiar foods were preferred (Fig. 2). Terpene diet intake was greater than tannin diet intake in both treatment $\mathrm{A}$, as hypothesized, (contrast estimate $=261 ; p<0.0001$ ) and treatment B (estimate $=-129, p=0.0049$ ), which was contrary to the a priori hypothesis. Terpene diet and tannin diet intakes were similar among subjects in treatment $\mathrm{C}$ (estimate $=-35.7 ; p=0.416$ ). The lower absolute value of the estimate and high probability associated with the contrast indicated that the hypothesis of no difference in diet intake among treatment $\mathrm{C}$ was supported.

\subsection{Experiment 2}

Analyses revealed that the only significant interaction was treatment $\times$ diet, indicating that experience did play a role in determining diet selection $(p=0.0353)$. There was also a significant day effect arising from reduced intake following the aversive event $(p=0.0173)$. Lithium chloride exposure in experiment 2 did little to change diet preferences observed among treatments in experiment 1 . As predicted, terpene diet intake was significantly higher than tannin diet intake for treatment A (estimate $=164$; $p<0.0001$ ). Contrary to prediction and similar to experiment 1 , terpene diet intake was also greater for treatment $\mathrm{B}$ (estimate $=-129 ; p=0.0008$ ). However, within treatment $\mathrm{C}$ a low estimate (32.6) and poor probability $(p=0.366)$ suggests that the a priori hypothesis of similar terpene and tannin diet intakes was supported. 

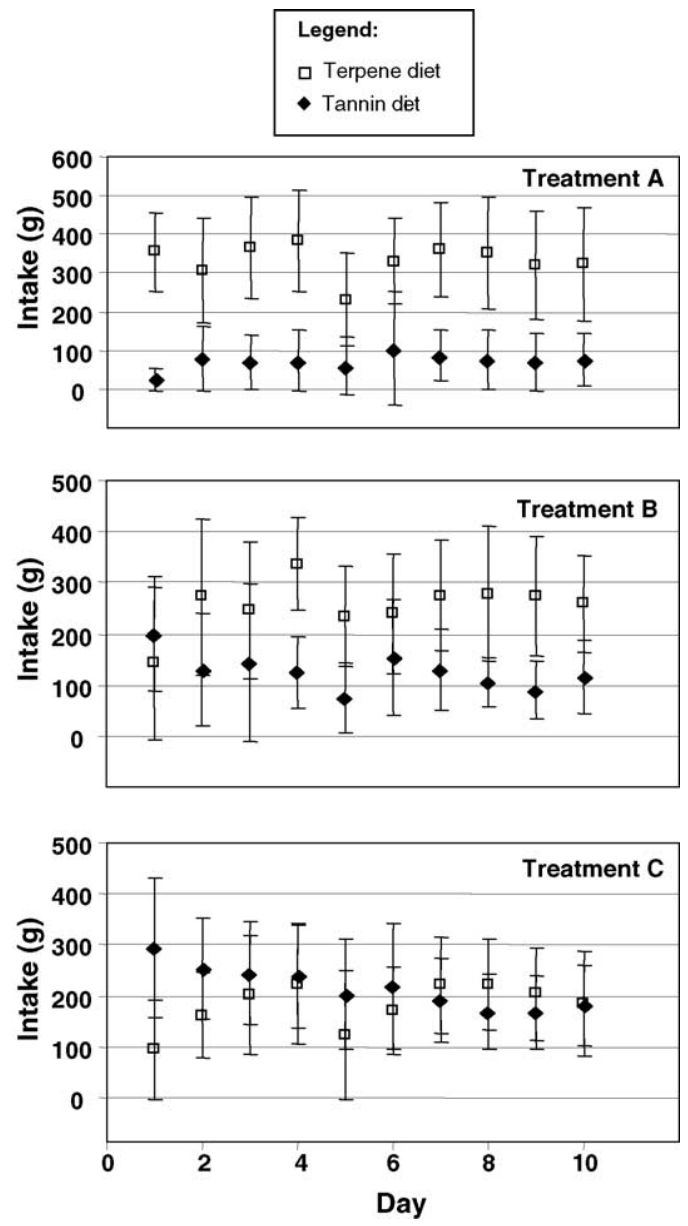

Fig. 2. Experiment 1: daily intake of terpene and tannin diets offered in a two-choice preference test following the 20-day experience period. Treatment A had experience with terpene diet only, treatment B tannin diet only, while treatment $\mathrm{C}$ had experience with both diets.

\subsection{Experiment 3}

Analyses identified treatment $\times$ diet $\times$ day as the highest-order significant interaction $(p=0.0348)$ along with diet $\times$ day $(p<0.0001)$ and pair $\times \operatorname{diet}(p=0.0003)$. These results suggest that treatment and diet effects varied over the course of the preference test. More importantly, intake of the two test diets was a function of which diet was paired with the aversive event. Post hoc comparison of intake data demonstrated that terpene diet was ingested in the greatest quantity when the tannin diet was paired with lithium-induced toxicosis (Fig. 3). Conversely, tannin diet intake was considerably reduced when the tannin diet was paired with $\mathrm{LiCl}$. When terpene diet was paired with $\mathrm{LiCl}$, terpene diet intake was 


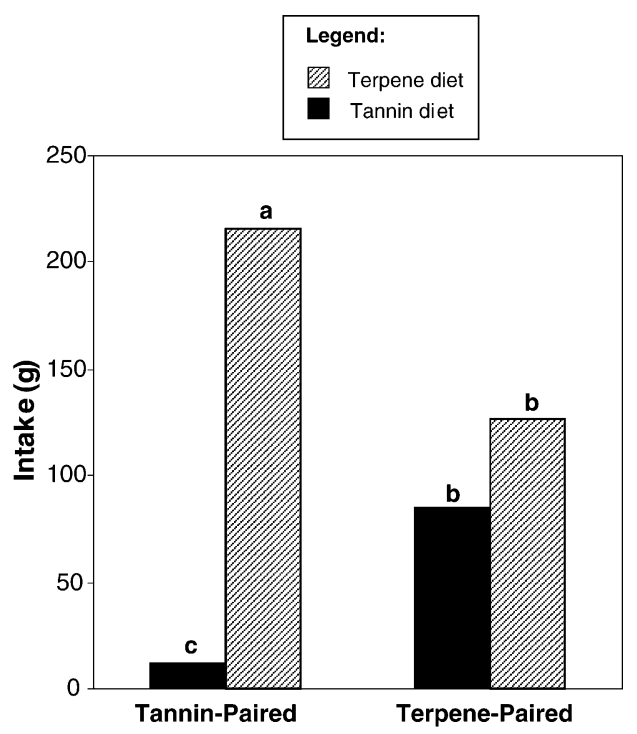

Fig. 3. Experiment 3: mean intake of terpene and tannin diets offered in two-choice preference tests following paired exposure of lithium chloride with one of the test diets. Means with different letters are significantly different at $\alpha=0.05$.

reduced (versus tannin-paired subjects) but tannin diet intake was not significantly different (Fig. 3).

Intake of the familiar terpene diet was greater than tannin diet intake among subjects in treatment A (estimate $=178 ; p<0.0001$ ). However, tannin diet intake did not exceed terpene diet intake as predicted for treatment B (estimate $=-131 ; p=0.0007$ ). Furthermore, the prediction of no difference between tannin and terpene diet intakes in treatment $C$ was not substantially supported. The probability was not high $(p=0.117)$ and the absolute value of the estimate was large $(-56.7)$.

Although tannin diet intake was largely suppressed among most subjects, one particular group of subjects continued to consume large quantities of tannin diet (Fig. 4). Post hoc analysis confirmed that treatment $\mathrm{C}$ tannin intake for terpene-paired subjects was greater than treatment A and B tannin intakes for similarly exposed subjects (estimate $=110$; $p=0.0155)$. However, the post hoc hypothesis that terpene diet intakes of treatments $\mathrm{A}$ and $\mathrm{B}$ when terpene-paired was greater than terpene diet intake of similarly exposed subjects in treatment $\mathrm{C}$, was not highly significant (estimate $=83.1 ; p=0.0621$ ). Although the importance of these results is tempered by the marginal significance attached to the treatment $\times$ pair $\times$ diet interaction $(p=0.0976)$, the nonconforming diet selection behavior displayed by treatment $\mathrm{C}$ is still interesting and amplified in experiment 4 .

\subsection{Experiment 4}

Both treatment and pair influenced diet selection as evidenced by a significant treatment $\times$ pair $\times$ diet effect $(p=0.0195)$. Changes in diet preference over the course of 


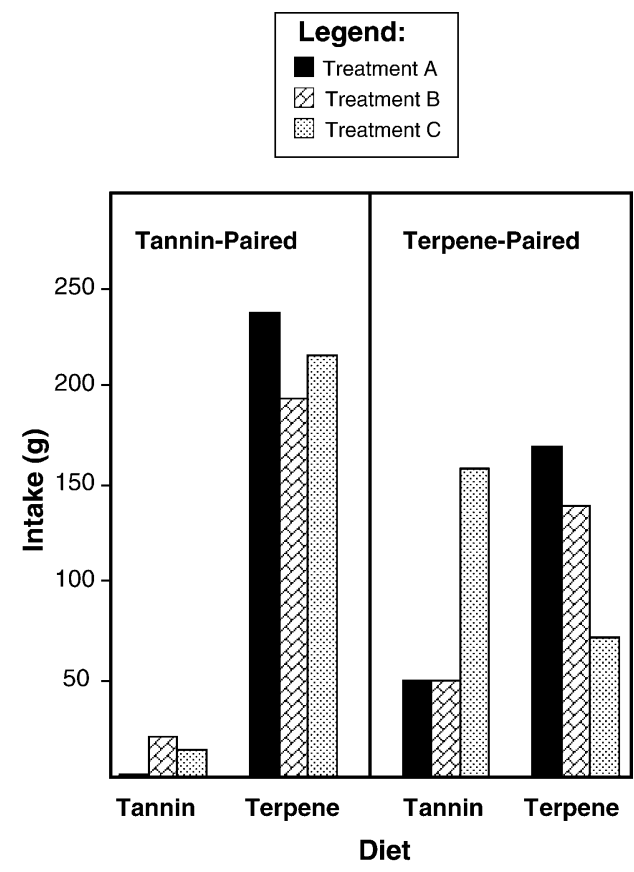

Fig. 4. Experiment 3: mean intake by treatment group. Terpene and tannin diets were offered in a two-choice preference test for 8 days following a single lithium chloride exposure that was paired with one of the test diets. The standard error of least-square means was $35.2 \mathrm{~g}$.

the 8-day preference test were also evident (diet $\times$ day; $p<0.0001$ ). Linear contrast did not support the hypothesis that CA diet intake would be lower than tannin and terpene diet intakes (estimate $=7.1 ; p=0.67$ ). In fact, post hoc analyses of the data highlight the markedly different tannin and CA diet intakes of treatment $C$ subjects (Fig. 5). The CA diet intakes of terpene-paired subjects from treatments $\mathrm{A}$ and $\mathrm{B}$ were significantly higher than similarly exposed subjects from treatment $C$ (estimate $=96.2 ; p=0.0216$ ). Likewise, tannin diet intake of treatment $\mathrm{C}$ subjects with terpene-paired exposures was dramatically higher than similarly exposed treatment A and B subjects (estimate $=127 ; p=0.0029$ ).

\section{Discussion}

\subsection{Experience}

The concentrations of terpenes (3\%) and quebracho (4\%) in the test diets were chosen to equate the antifeedant properties of the foods as evidenced by intake during the experience period. A previous study with sheep employing a similar terpene concentration $(2.9 \%)$ and much higher tannin concentration (15\%) resulted in greater intake of terpene-containing food versus tannin-containing food in single-choice tests (Villalba et al., 2004). 


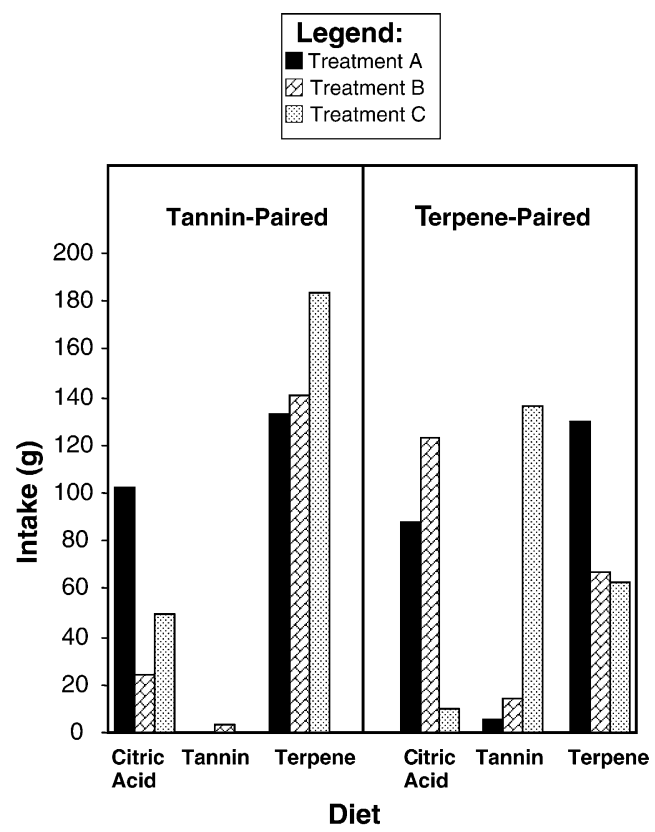

Fig. 5. Experiment 4: mean intake by treatment group and experiment-3 exposure. Terpene, tannin, and citric acid diets were offered simultaneously in association with a single lithium chloride exposure. Following exposure, the same diets were offered in a three-choice preference test for 8 days. The standard error of least-square means was $33.2 \mathrm{~g}$.

For both treatments $\mathrm{B}$ and $\mathrm{C}$, a neophobic response to the tannin diet was observed (Fig. 1). However, there was no evidence of a conditioned aversion to the tannin diet during the experience portion of the study. Subjects ate increasingly more of the tannin diet until a stable intake level was achieved. Once subjects had several feeding bouts with the tannincontaining food, intake of tannin diet did not differ between treatments B and C. Food neophobia is characterized by initial avoidance followed by attenuation after experience with the food (i.e., with repeated exposures animals learn that novel foods are safe). Foods are avoided for no other apparent reason than they are 'new' or 'strange'. Neophobia is a common strategy employed by mammals to avoid toxicosis from ingestion of unfamiliar foods (Launchbaugh and Provenza, 1994). The magnitude and persistence of neophobic responses can be a function of flavor strength. Strong flavors were initially avoided by lambs and weaker flavors were preferred (Augner et al., 1998). Likewise, the tannin diet in this study may have possessed strong flavor characteristics relative to the training and terpene diets and elicited a neophobic response.

Twenty days was considered ample time for subjects to became familiar with the test diets. Experience may produce several behavioral responses relevant to this study. First, aversions become more difficult to form, or lack persistence, when animals are experienced with a food (Burritt and Provenza, 1996). As few as 7 days experience with a food can be sufficient for subjects to learn the food is safe and attenuate aversions. Conversely, lack of 
experience increases the likelihood that negative postingestive consequences will be associated with a food (Kalat, 1974). Experience with toxins may also yield physiological and morphological changes in the herbivore that increase tolerance of the toxin. Goats with 19 days experience with tannin-containing forage had increased reticulorumen capacity and altered nitrogen metabolism as compared to inexperienced goats (Distel and Provenza, 1991). Experience with plant secondary metabolites can also induce enzymatic pathways for detoxification (Boyle and McLean, 2004).

\subsection{Experiment 1}

Experiment 1 was designed to evaluate the influence of experience on diet selection. The a priori hypotheses of this experiment were based upon the primary assumption that, antifeedant properties of the foods being equal, herbivores would prefer the familiar diet. However, familiarity with the terpene diet was not a prerequisite for its preference versus the tannin diet. In fact, daily experience with the tannin diet (treatment B) produced a preference for terpene diet. These results indicate that negative postingestive consequences from daily ingestion of tannins far exceeded the consequences of repeated terpene ingestion-yielding a preference for the terpene diet in two-choice tests. The aversive qualities of condensed tannins have been previously demonstrated with goats (Provenza et al., 1994). However, tannin-induced aversions were apparently minimized in this study by reducing the frequency of tannin diet ingestion. Alternating tannin and terpene experience (treatment C) promoted greater intake of the tannin diet during the preference test as evidenced by no preference versus the terpene diet.

\subsection{Experiment 2}

Affective learning generates avoidance of food(s) associated with negative postingestive consequences and preference for foods associated with positive consequences (Provenza, 1995a). Lithium chloride is frequently employed as the unconditional stimulus in FAL experiments because it produces mild gastrointestinal distress that is readily associated with salient flavor cues ingested within hours of $\mathrm{LiCl}$ administration. Experiment 2 was designed to determine which food would be associated with an aversive event produced by $\mathrm{LiCl}$. Accordingly, only $100 \mathrm{~g}$ of each diet was offered during the exposure phase to promote consumption of both diets. The a priori assumption of this experiment was that herbivores would 'blame' the postingestive consequences of lithium-induced toxicosis on the least familiar food. Contrary to prediction, the unfamiliar terpene diet was preferred versus the tannin diet among treatment B subjects.

Negative consequences are associated with novel foods (Kalat, 1974) and foods that previously caused illness (Burritt and Provenza, 1996). Prior illness resulting from repeated tannin ingestion in treatment $\mathrm{B}$ caused those subjects to associate the negative consequences of $\mathrm{LiCl}$ with the tannin diet. Conversely, treatment $\mathrm{C}$ had difficulty associating lithium-induced toxicosis with either diet because alternating exposure to the tannin diet did not produce negative consequences. Thus, treatment $\mathrm{C}$ had learned that both foods were safe. Both learned aversions and learned safety play significant roles in the diet selection of herbivores (Provenza et al., 1994). 


\subsection{Experiment 3}

The a priori hypotheses for experiment 3 were generated from the assumption that prior experience with the foods would identify them as 'safe' and prevent acquisition of an aversion from a single association with $\mathrm{LiCl}$. The results of experiment 3 demonstrate that when specifically paired with $\mathrm{LiCl}$, tannin diet was associated with the postingestive consequences regardless of prior experience (Figs. 3 and 4). Conversely, terpene-paired $\mathrm{LiCl}$ events failed to generate avoidance of the terpene diet in treatments $\mathrm{A}$ and $\mathrm{B}$. These results indicate that toxic effects of tannin consumption overshadow single aversive events with $\mathrm{LiCl}$ and terpenes, while single administration of $\mathrm{LiCl}$ with tannin potentiates tannin aversions. Only terpene-paired treatment $\mathrm{C}$ subjects demonstrated a preference for the tannin diet (Fig. 4). This is further evidence that the alternate day experience regimen minimized the toxic effects of tannins.

\subsection{Experiment 4}

A novel flavor was introduced in experiment 4. As the last of the experiments, the subjects had increased experience with the terpene and tannin diets and two prior $\mathrm{LiCl}$ exposures - one paired with a specific diet (experiment 3 ) and one in conjunction with both diets (experiment 2). The mass of diets offered in experiment 4 (50 g each) was limited on the day of exposure to promote consumption of each diet prior to a third $\mathrm{LiCl}$ administration.

The a priori hypothesis that CA diet intake would be lower than terpene and tannin diet intake was based on the assumption that a novel food would be avoided regardless of previous experience when offered in conjunction with $\mathrm{LiCl}$. Tannin-paired subjects continued to avoid tannin diet in experiment 4 , even in the presence of a novel flavor (CA). Citric acid has been demonstrated to be a salient cue when added to a familiar food (Kimball et al., 2002). Furthermore, sheep avoidance of CA-flavored food was persistent when alternative foods were available, regardless of the nutritive quality of the alternatives. However, in this study tannin-paired subjects were more likely to consume the novel food than the tannin diet because they had acquired an aversion to the tannin diet. Only terpenepaired subjects in treatment $\mathrm{C}$ demonstrated avoidance of CA diet because these were the only subjects to have learned that both the terpene and tannin diets were safe (i.e., they did not produce negative postingestive consequences; Fig. 5). These results further demonstrate that subjects with daily tannin diet experience (treatment B) acquired flavor aversions differently than subjects with every-other-day experience (treatment $\mathrm{C}$ ). Furthermore, it is probable that the toxic effects of the tannin diet were the basis of this difference.

\subsection{General discussion}

Goats experienced with tannins can consume more tannin-containing food than inexperienced animals (Distel and Provenza, 1991). Conversely, prior experience with terpenes did not promote increased intake of terpene-containing foods by goats (Pritz et al., 1997). The experiments described here further demonstrate that not all toxins, nor all experiences, are equivalent. Both experience and toxic effects of foods influence how 
aversions are acquired and diets are selected. The differences observed for tannins and terpenes in this study may be related to their toxic properties and consequences exerted on the herbivore.

Toxicity of phytochemicals to ruminants is subject to many factors including concentration, ingestion rate, microbial transformations in the rumen, adsorption rate, metabolism, and elimination (Smith, 1992). An important difference between tannin and terpene toxicities for this study may be clearance rate. Clearance of terpenes is thought to be rapid in mammals (Sorensen and Dearing, 2003), while tannin-induced suppression of intake can last up to 3 days (Aharoni et al., 1998). The $48 \mathrm{~h}$ interval between each tannin diet-feeding bout in treatment $\mathrm{C}$ may have provided sufficient time for adsorption, detoxification, and elimination processes to occur before the goats' next interaction with the food. Conversely, daily experience with tannin diet (treatment B) may have significantly burdened these processes and resulted in a greater metabolic cost to the subjects. Though detoxification effectively eliminates toxins from the body, it is a costly biochemical process (Illius and Jessop, 1995).

Treatment $\mathrm{C}$ allowed diets to be mixed in a complementary fashion, as opposed to treatment $\mathrm{B}$ (subjects could not escape the negative consequences of tannins during the experience portion of the study), or treatment A (toxic tannin diet was novel). Terpenes and tannins have been previously shown to be complimentary in sheep (Villalba et al., 2004). However, complimentary toxins have typically been studied by offering them in the same feeding bout. These results indicate that toxins can also be complimentary when consumed on different days.

\subsection{Implications for flavor aversion studies and applied flavor aversion learning}

It has been stated that "it is impossible to conduct an experiment on food selection that is not affected by experience, or a lack of it" (Provenza, 1995b). This study demonstrates how differing experiences influenced acquisition of flavor aversions. It is not difficult to imagine how unaccounted for experiences could greatly confound the interpretation of other studies of diet selection. Further complicating the issue, experience is not limited to food encounters of the individual herbivore. Experience can also arise from exposures in utero (Nolte et al., 1992; Nolte and Mason, 1995), maternal sources (Nolte et al., 1990; Nolte and Provenza, 1992), and from observing conspecifics (Galef, 1997; Galef and Whiskin, 2001).

These results further suggest that physiological and morphological differences may preclude the use of goats as physiological models for wild ungulates. For example, goats and deer may respond quite differently to tannins. Goats do not possess salivary proteins capable of binding to tannins and minimizing their deleterious effects on digestibility (Distel and Provenza, 1991), while these proline-rich proteins are present in saliva of mule deer (Robbins et al., 1991). Thus, mule deer would be expected to tolerate tannincontaining foods better and respond differently to these same experiments. However, studies conducted with domestic ungulates may provide insight into behavioral aspects of diet selection in wild ungulates because integration of foraging cues and postingestive consequences is pervasive among herbivores (Provenza, 1995c).

This study also has implications for applied flavor aversion learning. Application of FAL to protect agricultural resources from wildlife depredation has received much 
attention. Both successes and failures have been reported (Mason, 1998; Mason et al., 2001). Despite many obstacles, FAL is still considered an attractive non-lethal approach to minimize wildlife depredation. Persistent aversions in the absence of the aversive agent (mimicry) are particularly desirable for economic and safety reasons. However, this study demonstrates the difficulties that may hinder acquisition of persistent learned aversions with relatively few exposures to the aversive agent. Specifically, aversions to the familiar terpene diet were not formed with a single $\mathrm{LiCl}$ exposure in experiment 2 . When lithium-induced toxicosis was paired with the terpene diet in experiment 3, subjects familiar with terpene diet ignored the presentation and instead acquired aversions to tannin diet. Conversely, subjects familiar with tannin diet readily acquired aversions to that diet with single $\mathrm{LiCl}$ exposures. Thus, an effort to protect a resource that is familiar to the offending herbivores may require multiple (or constant) exposures to the aversive agent to yield persistent avoidance. Limited exposure may not only fail to condition an aversion to the target resource, but may also facilitate acquisition of an aversion to a different forage item.

\section{Conclusions}

The disparity of toxic consequences resulting from ingestion of the tannin and terpenecontaining diets were not obvious from experience period intake, but became readily apparent when the diets were offered in conjunction with $\mathrm{LiCl}$-induced aversions. Subjects that had little experience with tannins (treatment A) or experienced prolonged effects from repeated ingestion (treatment $\mathrm{B}$ ) readily associated the negative consequences from $\mathrm{LiCl}$ exposure with the tannin diet. Conversely, subjects with alternating daily experience with tannins (treatment $\mathrm{C}$ ) did not acquire aversions to the tannin diet unless it was specifically paired with $\mathrm{LiCl}$ exposure. At the same time, aversions were rarely formed to the terpene diet when the tannin diet was present, even when terpene diet was specifically paired with $\mathrm{LiCl}$ exposure. These results are consistent with herbivore avoidance of a toxic food mediated by flavor aversion learning (Provenza, 1995c).

\section{Acknowledgements}

The authors are grateful for the assistance of Ms. Vida Billings in the conduct of the experiments. The review comments of Scott Werner and two anonymous reviewers were greatly appreciated. A portion of this research was funded by USDA CSREES IFAFS Program Code 14.1: Alternative Natural Resource Management Practices for Private Lands-Grant \# 2001-52103-11215.

\section{References}

Aharoni, Y., Gilboa, N., Silanikove, N., 1998. Models of suppressive effect of tannins. Analysis of the suppressive effect of tannins on ruminal degradation by compartmental models. Anim. Feed Sci. Tech. 71, $251-267$.

Augner, M., Provenza, F.D., Villalba, J.J., 1998. A rule of thumb in mammalian herbivores? Anim. Behav. 56, $337-345$. 
Bell, C.M., Harestad, A.S., 1987. Efficacy of pine oil as repellent to wildlife. J. Chem. Ecol. 13, 1409-1417.

Boyle, R.R., Mclean, S., 2004. Constraint of feeding by chronic ingestion of 1,8-cineole in the brushtail possum (Trichsurus vulpecula). J. Chem. Ecol. 30, 757-775.

Bryant, J.P., Provenza, F.D., Pastor, J., Reichardt, P.B., Clausen, T.P., Dutoit, J.T., 1991. Interactions between woody-plants and browsing mammals mediated by secondary metabolites. Ann. Rev. Ecol. Syst. 22, 431-446.

Bryant, J.P., Reichardt, P.B., Clausen, T.P., 1992. Chemically mediated interactions between woody-plants and browsing mammals. J. Range Manage. 45, 18-24.

Burritt, E.A., Provenza, F.D., 1996. Amount of experience and prior illness affect the acquisition and persistence of conditioned food aversions in lambs. Appl. Anim. Behav. Sci. 48, 73-80.

Burritt, E.A., Provenza, F.D., 2000. Role of toxins in intake of varied diets by sheep. J. Chem. Ecol. 26, 19912005.

Clausen, T.P., Provenza, F.D., Burritt, E.A., Reichardt, P.B., Bryant, J.P., 1990. Ecological implications of condensed tannin structure - a case study. J. Chem. Ecol. 16, 2381-2392.

Dawson, J.M., Buttery, P.J., Jenkins, D., Wood, C.D., Gill, M., 1999. Effects of dietary quebracho tannin on nutrient utilisation and tissue metabolism in sheep and rats. J. Sci. Food Agric. 79, 1423-1430.

Dearing, M.D., Mangione, A.M., Karasov, W.H., 2002. Ingestion of plant secondary compounds causes diuresis in desert herbivores. Oecologia 130, 576-584.

Dimock, E.J., Silen, R.R., Allen, V.E., 1976. Genetic resistance in Douglas-fir to damage by snowshoe hare and black-tailed deer. Forest Sci. 22, 106-121.

Distel, R.A., Provenza, F.D., 1991. Experience early in life affects voluntary intake of blackbrush by goats. J. Chem. Ecol. 17, 431-450.

Estell, R.E., Fredrickson, E.L., Anderson, D.M., Havstad, K.M., Remmenga, M.D., 1998. Relationship of tarbush leaf surface terpene profile with livestock herbivory. J. Chem. Ecol. 24, 1-12.

Farentinos, R.C., Capretta, P.J., Kepner, R.E., Littlefield, V.M., 1981. Selective herbivory in tassel-eared squirrels - role of monoterpenes in ponderosa pines chosen as feeding trees. Science 213, 1273-1275.

Galef, B.G., 1997. Norway rats' communication about foods and feeding sites. In: Mason, J.R. (Ed.), Proceedings of the Second DWRC Symposium Series, National Wildlife Research Center, Fort Collins, CO, Repellents Wildlife Manage. 185-201.

Galef, B.G., Whiskin, E.E., 2001. Interaction of social and individual learning in food preferences of Norway rats. Anim. Behav. 62, 41-46.

Illius, A.W., Jessop, N.S., 1995. Modeling metabolic costs of allelochemical ingestion by foraging herbivores. J. Chem. Ecol. 21, 693-719.

Kalat, J.W., 1974. Taste salience depends on novelty, not concentration, in taste-aversion learning in rat. J. Comp. Physiol. Psych. 86, 47-50.

Kimball, B.A., Nolte, D.L., Engeman, R.M., Johnston, J.J., Stermitz, F.R., 1998. Chemically mediated foraging preference of black bears (Ursus americanus). J. Mammal. 79, 448-456.

Kimball, B.A., Provenza, F.D., Burritt, E.A., 2002. Importance of alternative foods on the persistence of flavor aversions: implications for applied flavor avoidance learning. Appl. Anim. Behav. Sci. 76, 249-258.

Launchbaugh, K.L., Provenza, F.D., 1994. The effect of flavor concentration and toxin dose on the formation and generalization of flavor aversions in lambs. J. Anim. Sci. 72, 10-13.

Mason, J.R., 1998. Mammal repellents: options and considerations for development. In: Baker, R.O., Crabb, A.C. (Eds.), Proceedings of the 18th Vertebrate Pest Conference, University of California, Davis, CA, pp. 325-329.

Mason, J.R., Shivik, J.A., Fall, M.W., 2001. Chemical repellents and other aversive strategies in predation management. Endanger. Spec. Update 18, 175-181.

McMahon, L.R., McAllister, T.A., Berg, B.P., Majak, W., Acharya, S.N., Popp, J.D., Coulman, B.E., Wang, Y., Cheng, K.J., 2000. A review of the effects of forage condensed tannins on ruminal fermentation and bloat in grazing cattle. Can. J. Plant Sci. 80, 469-485.

Miyazawa, M., Watanabe, H., Kameoka, H., 1997. Inhibition of acetylcholinesterase activity by monoterpenoids with a $p$-menthane skeleton. J. Agric. Food Chem. 45, 677-679.

Nolte, D.L., Mason, J.R., 1995. Maternal ingestion of ortho-aminoacetophenone during gestation affects intake by offspring. Physiol. Behav. 58, 925-928.

Nolte, D.L., Provenza, F.D., 1992. Food preferences in lambs after exposure to flavors in milk. Appl. Anim. Behav. Sci. 32, 381-389. 
Nolte, D.L., Provenza, F.D., Balph, D.F., 1990. The establishment and persistence of food preferences in lambs exposed to selected foods. J. Anim. Sci. 68 (998), 998-1002.

Nolte, D.L., Provenza, F.D., Callan, R., Panter, K.E., 1992. Garlic in the ovine fetal environment. Physiol. Behav. 52, 1091-1093.

Pritz, R.K., Launchbaugh, K.L., Taylor, C.A., 1997. Effects of breed and dietary experience on juniper consumption by goats. J. Range Manage. 50, 600-606.

Provenza, F.D., 1995a. Postingestive feedback as an elementary determinant of food preference and intake in ruminants. J. Range Manage. 48, 2-17.

Provenza, F.D., 1995b. Role of learning in food preferences of ruminants: Greenhalgh and Reid revisited. In: Engelhardt, W.V., Leonhard-Marek, S., Breves, G., Giesecke, D. (Eds.), Ruminant Physiology: Digestion, Metabolism, Growth and Reproduction. Ferdinand Enke Verlag, Stuttgart, Germany, pp. 223-247.

Provenza, F.D., 1995c. Tracking variable environments - there is more than one kind of memory. J. Chem. Ecol. 21, 911-923.

Provenza, F.D., Lynch, J.J., Burritt, E.A., Scott, C.B., 1994. How goats learn to distinguish between novel foods that differ in postingestive consequences. J. Chem. Ecol. 20, 609-624.

Rangen, S.A., Hawley, A.W.L., Hudson, R.J., 1994. Relationship of snowshoe hare feeding preferences to nutrient and tannin content of 4 conifers. Can. J. Forest Res. 24, 240-245.

Reichardt, P.B., Bryant, J.P., Mattes, B.R., Clausen, T.P., Chapin, F.S., Meyer, M., 1990. Winter chemical defense of Alaskan balsam poplar against snowshoe hares. J. Chem. Ecol. 16, 1941-1959.

Rice, W.R., 1989. Analyzing tables of statistical tests. Evolution 43, 223-225.

Robbins, C.T., Hanley, T.A., Hagerman, A.E., Hjeljord, O., Baker, D.L., Schwartz, C.C., Mautz, W.W., 1987. Role of tannins in defending plants against ruminants - reduction in protein availability. Ecology 68, 98-107.

Robbins, C.T., Hagerman, A.E., Austin, P.J., McArthur, C., Hanley, T.A., 1991. Variation in mammalian physiological-responses to a condensed tannin and its ecological implications. J. Mammal. 72, 480-486.

Roy, J., Bergeron, J.M., 1990. Role of phenolics of coniferous trees as deterrents against debarking behavior of meadow voles (Microtus pennsylvanicus). J. Chem. Ecol. 16, 801-808.

SAS. SAS/STAT [8.2], 1999. Cary, NC, SAS Institute Inc.

Smith, G.S., 1992. Toxification and detoxification of plant-compounds by ruminants - an overview. J. Range Manage. 45, 25-30.

Snyder, M.A., 1992. Selective herbivory by aberts squirrel mediated by chemical variability in ponderosa pine. Ecology 73, 1730-1741.

Sorensen, J.S., Dearing, M.D., 2003. Elimination of plant toxins by herbivorous woodrats: revisiting an explanation for dietary specialization in mammalian herbivores. Oecologia 134, 88-94.

Sunnerheim-Sjoberg, K., Hamalainen, M., 1992. Multivariate study of moose browsing in relation to phenol pattern in pine needles. J. Chem. Ecol. 18, 659-672.

Villalba, J.J., Provenza, F.D., Han, G.-D., 2004. Experience influences diet mixing by herbivores: implications for plant biochemical diversity. Oikos. 107, 100-109. 